\title{
Assessing the Psychological Impact of the Pandemic COVID - 19 in Uninfected High-Risk Population
}

\author{
Sami Mustafa Jafar Ahmed', Bashir Ali Awadelgeed ${ }^{2}$, Elhadi Miskeen $\mathbb{1}^{3,4}$ \\ 'Department of Family and Community Medicine,Al Kharj Military Industries Corporation Hospital, Riyadh, Saudi Arabia; ${ }^{2}$ Chemistry Department, \\ Faculty of Science, Bakht Er-Ruda University, Ed Dueim, Sudan; ${ }^{3}$ Department of Obstetrics and Gynaecology, College of Medicine, University of Bisha, \\ Bisha, Saudi Arabia; ${ }^{4}$ Department of Obstetrics and Gynaecology, Faculty of Medicine, University of Gezira, Wad Medani, Sudan
}

Correspondence: Sami Mustafa Jafar Ahmed, Department of Family and Community Medicine, Al Kharj Military Industries Corporation Hospital, Riyadh, Saudi Arabia, Tel+966559131609, Email Samimustafa2009@hotmail.com

\begin{abstract}
Purpose: To assess the impact of the COVID-19 pandemic on the psyche of uninfected people with chronic diseases in the Elduim community, White Nile State, Sudan, during the COVID -19 pandemic.

Methods: We used a generalized anxiety disorder scale (GAD -7) and a patient health questionnaire (PHQ-9) for psychological assessment. The study included two hundred thirty-four participants; all participants with a chronic disease but not infected with COVID -19 were between 24 and 65 years of age. Residents of the study area were randomly selected. Descriptive statistics and a $t$-test were used for associations with a p-value of 0.05 or less.

Results: This study found that anxiety rated by GAD 7 was either mild (18, 7.7\%), moderate (98, 41.9\%), or severe (41, 17.5\%) among participants. PHQ 9-rated depression showed 22 (9.4\%) mild depression, most of them in participants aged 36-44 years. Participants with kidney disease showed major depression 11 (42.31\%). Factors that significantly affected anxiety scores were age $24-35$ years $(\mathrm{P}=0.002)$, university graduates $(\mathrm{P}<0.000)$, married $(\mathrm{P}<0.000)$, those with diabetes and hypertension $(\mathrm{P}=0.041)$, and urban residents $(\mathrm{P}<0.023)$. Those who had secondary education were married and smoked were significantly more likely to have major depression than those with another educational status $(\mathrm{p}<0.05)$.

Conclusion: COVID 19 pandemic had a significant impact on the psyche of uninfected people with chronic diseases in Sudan, and significant associated factors were identified. Unique interventions are strongly recommended to reduce the psychological impact of the COVID 19 pandemic.
\end{abstract}

Keywords: COVID-19, psychological impact, chronic disease, anxiety, depression

\section{Introduction}

In late 2019, the novel coronavirus, abbreviated COVID19, in Wuhan, China, became a global pandemic, ${ }^{1}$ which is of great $_{\text {concern }}{ }^{-3}$ and has a significant impact on the psychological state of individuals. ${ }^{4,5}$ Anxiety and depression associated with the pandemic have been reported, ${ }^{6}$ with many clinical features. Specific and nonspecific clinical features related to COVID-19 include clinical characteristics of mental disorders. ${ }^{7-10}$ The co-occurrence of mental problems negatively affects the prognosis of treatment of respiratory symptoms of the disease. ${ }^{11}$ Few sporadic case reports in the literature $^{12}$ showed that severe disease with long-lasting symptoms was more susceptible. ${ }^{13}$ Fear of becoming infected increased as the pandemic progressed, especially after the declaration of WHO and the change in physical distance. Several factors added additional stress, including living away from Family for many reasons, the elderly, and social media contributed even more to the current situation. ${ }^{14,15}$

The ongoing pandemic has affected the efficiency of health care systems worldwide. In Africa, the situation is weaker because the health sector in most African countries is vulnerable, which will overwhelm health systems. In particular, the vulnerable population with chronic diseases needs regular health care. ${ }^{16}$ The associated social stigma poses an additional challenge for control and prevention COVID -19. Sudan has a high mortality rate due to limited testing and health 
services. Patients with chronic diseases are at higher risk. The health system needs urgent support to improve health care and reporting and monitoring services. ${ }^{17}$

Chronic diseases such as diabetes mellitus, hypertension, renal disease, respiratory disease, and gastrointestinal disease pose a high risk for infection, morbidity, and mortality, in addition to preexisting comorbidities. ${ }^{18}$ In addition to physical health, COVID -19 also affects mental health and increases stress for patients with chronic diseases. The rapid outbreak of the COVID -19 pandemic resulted in severe illness and even death. ${ }^{19}$

The regularly reported deaths and high cases are staggering and full of stress, especially in those with known risk factors and long-term medications. This study assessed the impact of the COVID -19 pandemic on the psyche of uninfected people with chronic diseases in Elduim locality, White Nile State, Sudan, during the COVID -19 pandemic.

\section{Method}

\section{Study Setting}

This is a descriptive cross-sectional study was conducted in primary health care (PHC) centers. PHC is the first point of contact for patient care. During the current COVID-19 pandemic, PHCs have been busy. Patients with chronic diseases are followed up regularly at PHCs and referred to tertiary facilities only if they develop complications. Health care in Sudan is mainly provided by primary health centers, rural Hospitals, and tertiary hospitals.

\section{Participants}

A total of 234 participants were enrolled in this study. All participants who had chronic disease but were not infected with COVID-19 were between 24 and over 65 years of age. Residents of the study area were randomly selected.

\section{Study Population}

The study population was uninfected Sudanese with chronic diseases who came to a PHC for routine care. Those who had COVID -19 infections were excluded from the study. They were included in the study population after giving their informed consent. We started data collection after received the opinion of the bioethics committee.

\section{Data Collection}

Relevant data were collected using a self-completion questionnaire that was validated by a panel of experts. Determine differences in anxiety and depression scores during the pandemic COVID -19 associated with some demographic variables such as sex, age, academic status, marital status, family size, smoking, type of chronic illness, occupation, and residence. A generalized anxiety disorder scale (GAD -7) and the Patient Health Questionnaire-9 (PHQ-9) scale were used as survey methods. Sources of information about the disease among the subjects also included radio and television, social media, and medical personnel.

\section{Anxiety Measurement}

From validation previously, ${ }^{20}$ we used the psychological evaluation, we used a scale of generalized anxiety disorders (GAD-7), and a patient health questionnaire (PHQ-9). Present of anxiety in the past two weeks and scored accordingly: (0-21) categorized impaired, were (0-4) minimum, (5-9) mild, (10-14) moderate, and (15-21) severe anxiety. ${ }^{21,22}$ Although there are several instruments for assessing or screening anxiety disorders, one of the most common anxiety disorders encountered in general medical practice and in general is generalized anxiety disorder (GAD). The GAD -7 scale was used. The GAD -7 is a valuable and effective tool for screening GAD and assessing severity in clinical practice and research.

\section{Measures of Depression Symptoms}

It was measured by a patient health questionnaire (PHQ-9). PHQ-9 was used as a screening and monitoring tool for severity determination and scaling. ${ }^{23,24}$ Ten questions evaluated depression; the answers were never, some days, most 
time, and always. Categorization was based on the two questions related to interest on activities and feelings (sad, hopeless or depressed).

\section{Statistical Analysis}

Data are analyzed using Statistical Package for Social Sciences software after being grouped and tabulated. Descriptive statistics and a $t$-test were used for associations. The data are expressed as mean \pm standard deviation. They are interpreted in the form of a statement, table, and figure - with a p-value of 0.05 or less.

\section{Results}

Two hundred and thirty four (234) participants were included in this study. More than half were female, 120 (51.28\%), and about 127 (54.2\%) participants were above 45 years. 164 (70.05\%) were attended secondary education and above. About 135 (57.69\%) were married, family size between (4-6) was a high percentage (41.45), most of the participants were not smoking (64.0\%). Diabetes and hypertension are more distributed diseases among the study sample (38.46\%) and $(36.75 \%)$ respectively, few were employed, $33(14.1 \%)$, social media was the mean source for collecting information about COVID-19 (38.03), and urban was a great place for residence for the participants $(89.74 \%)$ (Table 1).

Table I Demographic Characteristics of the Participants $(n=234)$

\begin{tabular}{|c|c|c|c|}
\hline Variable & Category & Frequency & Percentage (\%) \\
\hline \multirow[t]{2}{*}{ Gender } & Male & 114 & (49) \\
\hline & Female & 120 & (5I) \\
\hline \multirow[t]{4}{*}{ Age } & $24-35$ & 32 & $(13.7)$ \\
\hline & $36-44$ & 75 & (32.1) \\
\hline & $45-64$ & 101 & $(43.10)$ \\
\hline & Over 65 & 26 & (II.10) \\
\hline \multirow[t]{5}{*}{ Educational status } & Illiterate & 15 & $(6.4 I)$ \\
\hline & Literate & 21 & $(8.97)$ \\
\hline & Primary school & 34 & $(14.53)$ \\
\hline & Secondary & 75 & $(32.05)$ \\
\hline & University & 89 & $(38.00)$ \\
\hline \multirow[t]{4}{*}{ Marital status } & Single & 59 & $(25.21)$ \\
\hline & Married & 135 & (57.69) \\
\hline & Widows & 25 & $(10.68)$ \\
\hline & Divorced & 15 & $(6.4 I)$ \\
\hline \multirow[t]{3}{*}{ Family size } & $1-3$ & 85 & $(36.32)$ \\
\hline & $4-6$ & 97 & $(41.45)$ \\
\hline & Over 6 & 52 & $(22.22)$ \\
\hline \multirow[t]{2}{*}{ Smoking } & Yes & 84 & $(36.0)$ \\
\hline & No & 150 & (64.0) \\
\hline
\end{tabular}

(Continued) 
Table I (Continued).

\begin{tabular}{|l|l|l|c|}
\hline Variable & Category & Frequency & Percentage (\%) \\
\hline \multirow{5}{*}{ Chronic disease } & Asthma & 07 & $(2.99)$ \\
\cline { 2 - 4 } & Cancer & 11 & $(4.70)$ \\
\cline { 2 - 4 } & Heart disease & 13 & $(5.56)$ \\
\cline { 2 - 4 } & Diabetes & 90 & $(38.46)$ \\
\cline { 2 - 4 } & Kidney disease & 26 & $(11.11)$ \\
\cline { 2 - 4 } & Hypertension & 86 & $(36.75)$ \\
\cline { 2 - 4 } & Liver disease & 01 & $(0.43)$ \\
\hline \multirow{5}{*}{ Employment status } & Employ & 201 & $(85.90)$ \\
\cline { 2 - 4 } & Non-Employ & 33 & $(14.10)$ \\
\hline \multirow{5}{*}{ Source information about COVID-19 } & T.V and radio & 117 & $(50.0)$ \\
\cline { 2 - 4 } & Social media & 89 & $(38.03)$ \\
\cline { 2 - 4 } & Health workers & 28 & $(11.97)$ \\
\hline \multirow{5}{*}{ Residence } & Urban & 210 & $(89.74)$ \\
\cline { 2 - 4 } & Rural & 24 & $(10.26)$ \\
\hline
\end{tabular}

Assessment of anxiety by GAD 7 revealed that it was mild in 18 (7.7\%), moderate in $98(41.9 \%)$, and severe in $41(17.5 \%)$. Factors significantly impact the presence of anxiety were age $(\mathrm{p}=0.00)$, university graduates had a high score $(\mathrm{P}<0.000)$, married people who have a family member over six had a significantly higher GAD -7 score than other family members $(\mathrm{P}<0.000)$. The participants who smoke are not significantly anxious $(\mathrm{P}<0.102)$. Participants suffering from diabetes and hypertension were significantly more anxious compared to other chronic diseases. Working participants $(\mathrm{P}=0.041)$, participants who used social media as a source of information ( $\mathrm{P}=0.023)$, and urban dwellers $(\mathrm{P}<0.023)$ had a significantly higher GAD7 score. Female, 45-64 years old, university graduate, married, with more than six family members, nonsmoker, with chronic diseases, employed, social media user, and urban dweller had a higher risk of developing severe anxiety. (Table 2).

PHQ9 Scale evaluates depression; 105 (92.1\%) of males perceived some degree of depression, with moderate and moderate-severe depression being the most common in 37 (32.46\%), then mild depression in 26 (22.8\%). Although not significantly linked, those who had a severe form of depression were 36-44 yrs $(\mathrm{p}<0.5)$. Those with secondary school degrees had significantly higher severe depression than other educational status $(p<0.046)$. Also, those who were married had significantly higher severe depression $(\mathrm{p}<0.012)$. The participants with diabetes were high mild depression 29 (32.22\%). Those who had kidney diseases were severely high depression $11(42.31 \%)$, there was no significant association statistically among smoking and residence with depressive levels $(\mathrm{p}<0.046)$. We can summarize that those who are female, have a high school degree, are married, have a large family, suffer from kidney disease, are employed, and get information from social media have a higher risk of developing severe depression. (Table 3).

\section{Discussion}

The current study examined the psychological impact (anxiety, depression) on the population suffering from a chronic disease. COVID 19 pandemic has significantly affected the psychological impact of people. A person with chronic illness was mainly concerned with the preventive measures recommended by $\mathrm{WHO}^{25}$

This study found that the psychological disorders among the participants were anxiety (35\%) and depression (29.4\%). These results are in agreement with a study conducted in Saudi Arabia where $28 \%{ }^{26}$ were reported during the current 
Table 2 The Sociodemographic Distribution of the Participants and Its Association with Anxiety $(\mathrm{N}=234)$

\begin{tabular}{|c|c|c|c|c|c|c|}
\hline \multirow[t]{2}{*}{ Variable } & \multirow[t]{2}{*}{ Category } & \multicolumn{4}{|c|}{ Anxiety Level N (\%) } & \multirow[t]{2}{*}{$P$-value } \\
\hline & & Minimal & Mild & Moderate & Severe & \\
\hline \multirow[t]{2}{*}{ Gender } & Male & $5(4.39)$ & $27(23.68)$ & $63(55.26)$ & $19(16.67)$ & \multirow[t]{2}{*}{0.025} \\
\hline & Female & $13(10.83)$ & $50(4 I .67)$ & $35(29.17)$ & $22(18.33)$ & \\
\hline \multirow[t]{4}{*}{ Age } & $24-35$ & $4(12.5)$ & $13(40.62)$ & $13(40.62)$ & $2(6.25)$ & \multirow[t]{4}{*}{0.002} \\
\hline & $36-44$ & $4(5.3)$ & $46(61.33)$ & $22(29.33)$ & $3(4.00)$ & \\
\hline & $45-64$ & $4(3.96)$ & $50(49.5)$ & $36(35.64)$ & II (I0.89) & \\
\hline & Over 65 & $2(7.69)$ & $12(46.15)$ & $7(26.92)$ & $5(19.23)$ & \\
\hline \multirow[t]{5}{*}{ Educational status } & Illiterate & $5(33.33)$ & $4(26.67)$ & $5(33.33)$ & $I(6.67)$ & \multirow[t]{5}{*}{0.000} \\
\hline & Literate & $6(28.57)$ & $3(14.29)$ & II (52.38) & $\mathrm{I}(4.76)$ & \\
\hline & Primary school & $2(5.88)$ & $19(55.88)$ & $10(29.41)$ & $3(8.82)$ & \\
\hline & Secondary & $\mathrm{II}(14.67)$ & $29(38.67)$ & $33(44)$ & $5(6.67)$ & \\
\hline & University & $2(2.25)$ & $55(61.80)$ & $21(23.60)$ & $\mathrm{II}(\mathrm{I} 2.36)$ & \\
\hline \multirow[t]{4}{*}{ Marital status } & Single & $13(22.03)$ & $22(37.29)$ & $22(37.29)$ & $2(3.39)$ & \multirow[t]{4}{*}{0.000} \\
\hline & Married & II (8.15) & $69(51.11)$ & $49(36.30)$ & $6(4.44)$ & \\
\hline & Widows & $4(16.00)$ & $14(56.0)$ & $2(8.00)$ & $5(20.00)$ & \\
\hline & Divorced & $7(46.67)$ & $3(20.0)$ & $I(6.67)$ & $4(26.67)$ & \\
\hline \multirow[t]{3}{*}{ Family size } & $1-3$ & $18(21.18)$ & $32(37.65)$ & $32(37.65)$ & $3(3.52)$ & \multirow[t]{3}{*}{0.001} \\
\hline & $4-6$ & $6(6.19)$ & $50(51.55)$ & $37(38.14)$ & $4(4.12)$ & \\
\hline & Over 6 & II (2I.I5) & $26(50.0)$ & $5(9.62)$ & $10(19.23)$ & \\
\hline \multirow[t]{2}{*}{ Smoking } & Yes & $24(28.57)$ & $31(36.90)$ & $27(32.14)$ & $3(3.57)$ & \multirow[t]{2}{*}{0.102} \\
\hline & No & $18(12.0)$ & $76(50.67)$ & $42(28.0)$ & $14(9.33)$ & \\
\hline \multirow[t]{7}{*}{ Chronic disease } & Asthma & $3(42.86)$ & $2(28.57)$ & I (I4.29) & I (I4.29) & \multirow[t]{7}{*}{0.000} \\
\hline & Cancer & $\mathrm{I}(9.09)$ & $4(36.36)$ & $5(45.45)$ & I (9.09) & \\
\hline & Heart disease & $2(15.38)$ & $3(23.08)$ & $7(53.85)$ & $\mathrm{I}(7.69)$ & \\
\hline & Diabetes & $24(26.67)$ & $35(38.89)$ & $29(32.22)$ & $2(2.22)$ & \\
\hline & Liver disease & 0.0 & 0.0 & 0.0 & $I(I 00.0)$ & \\
\hline & Hypertension & $4(4.65)$ & $48(55.81)$ & $26(30.23)$ & $8(9.30)$ & \\
\hline & Kidney disease & $7(26.92)$ & $14(53.85)$ & I (3.85) & $4(15.38)$ & \\
\hline \multirow[t]{2}{*}{ Employment status } & Employ & $31(15.42)$ & $89(44.28)$ & $66(32.84)$ & $13(6.47)$ & \multirow[t]{2}{*}{0.041} \\
\hline & Non-Employ & II(33.33) & $17(5|.5|)$ & I (3.03) & $4(12.12)$ & \\
\hline \multirow[t]{3}{*}{ Source information about COVID-I9 } & $\mathrm{T} . \mathrm{V}$ and radio & $20(17.09)$ & $42(35.90)$ & $45(38.46)$ & $10(8.55)$ & \multirow[t]{3}{*}{0.023} \\
\hline & Social media & $4(4.49)$ & $42(47.19)$ & $33(37.08)$ & $10(11.24)$ & \\
\hline & Health workers & $7(25.0)$ & $16(57.14)$ & $\mathrm{I}(3.57)$ & $4(14.29)$ & \\
\hline
\end{tabular}


Table 2 (Continued).

\begin{tabular}{|l|l|l|l|l|l|l|}
\hline Variable & \multirow{2}{*}{ Category } & \multicolumn{5}{|c|}{ Anxiety Level N (\%) } \\
\cline { 3 - 7 } & & & Minimal & Mild & Moderate & Severe \\
\hline Residence & Urban & $24(11.43)$ & $90(42.86)$ & $78(37.14)$ & $20(9.52)$ & 0.023 \\
\cline { 2 - 7 } & Rural & $7(29.17)$ & $12(50.0)$ & $1(4.17)$ & $4(16.67)$ \\
\hline
\end{tabular}

COVID 19 pandemic, $32 \%{ }^{26}$ in Spain, and $28 \%$ in a systematic review reported $28 \%{ }^{27}$ Our results were lower than those reported in India for anxiety $43 \%$ and depression $39 \%{ }^{28}$

We found that being female is more likely to develop anxiety and depression during the pandemic COVID 19. The results are consistent with findings from India, Iran, and China. ${ }^{29-32}$ Women's increased susceptibility to chronic illness, suffering more than men, is related to emotional symptoms. ${ }^{33}$

Table 3 The Sociodemographic Distribution of the Participants and Its Association with Depression $(\mathrm{N}=234)$

\begin{tabular}{|c|c|c|c|c|c|c|c|}
\hline \multirow[t]{2}{*}{ Variable } & \multirow[t]{2}{*}{ Category } & \multicolumn{5}{|c|}{ Depression Level } & \multirow[t]{2}{*}{ P-value } \\
\hline & & Minimal & Mild & Moderate & M. Severe & Severe & \\
\hline \multirow[t]{2}{*}{ Gender } & Male & $9(7.89)$ & $26(22.8 I)$ & 37 (32.46) & $37(32.46)$ & $5(4.39)$ & \multirow[t]{2}{*}{0.032} \\
\hline & Female & $13(10.83)$ & $12(10.0)$ & $20(16.67)$ & $45(37.5)$ & $30(25.0)$ & \\
\hline \multirow[t]{4}{*}{ Age } & $24-35$ & $7(21.89)$ & $4(12.5)$ & $4(12.5)$ & $13(40.62)$ & $4(12.5)$ & \multirow[t]{4}{*}{0.59} \\
\hline & $36-44$ & $23(30.67)$ & $18(24.0)$ & II (I4.67) & $12(16.0)$ & II (14.67) & \\
\hline & $45-64$ & $31(30.69)$ & $22(21.78)$ & $25(24.75)$ & $14(13.86)$ & $9(8.91)$ & \\
\hline & Over 65 & $6(23.08)$ & $4(15.38)$ & $3(I I .54)$ & $7(26.92)$ & $6(23.08)$ & \\
\hline \multirow[t]{5}{*}{ Educational status } & Illiterate & $4(26.67)$ & $5(33.33)$ & $3(20.0)$ & $I(6.67)$ & $2(13.33)$ & \multirow[t]{5}{*}{0.046} \\
\hline & Literate & $3(14.29)$ & $8(38.1)$ & $4(19.05)$ & $4(19.05)$ & $2(9.52)$ & \\
\hline & Primary school & $6(17.65)$ & $\mathrm{I}(2.94)$ & $5(|4.7|)$ & $4(11.76)$ & I8 (52.94) & \\
\hline & Secondary & $18(24.0)$ & $20(26.67)$ & II (I4.67) & $7(9.33)$ & $19(25.33)$ & \\
\hline & University & $\mathrm{II}(12.36)$ & $6(6.74)$ & $38(50.67)$ & $17(19.10)$ & $17(19.10)$ & \\
\hline \multirow[t]{4}{*}{ Marital status } & Single & $21(35.60)$ & $9(15.25)$ & $6(10.17)$ & $6(10.17)$ & I7 (28.8I) & \multirow[t]{4}{*}{0.012} \\
\hline & Married & $6(4.44)$ & $14(10.37)$ & $20(\mid 4.8 I)$ & $45(33.33)$ & $50(37.04)$ & \\
\hline & Widows & $I(4.0)$ & $2(8.0)$ & $8(32.0)$ & II (44.0) & $3(12.0)$ & \\
\hline & Divorced & $I(6.67)$ & I (6.67) & $6(4.0)$ & $4(26.67)$ & $3(20.0)$ & \\
\hline \multirow[t]{3}{*}{ Family size } & $1-3$ & $2 I(24.7 I)$ & $9(10.59)$ & $8(9.4 I)$ & $18(2 \mid .18)$ & $29(34.12)$ & \multirow[t]{3}{*}{0.003} \\
\hline & $4-6$ & $4(4.12)$ & $12(12.37)$ & $14(14.43)$ & $33(34.02)$ & $34(35.05)$ & \\
\hline & Over 6 & 6 (II.54) & $5(9.62)$ & $18(34.62)$ & $15(28.85)$ & $8(15.38)$ & \\
\hline \multirow[t]{2}{*}{ Smoking } & Yes & $33(39.29)$ & $19(22.62)$ & $13(15.48)$ & $9(10.7 I)$ & $10(11.90)$ & \multirow[t]{2}{*}{0.96} \\
\hline & No & $43(28.67)$ & $35(23.33)$ & 31 (20.67) & $14(9.33)$ & I7 (II.33) & \\
\hline
\end{tabular}

(Continued) 
Table 3 (Continued).

\begin{tabular}{|c|c|c|c|c|c|c|c|}
\hline \multirow[t]{2}{*}{ Variable } & \multirow[t]{2}{*}{ Category } & \multicolumn{5}{|c|}{ Depression Level } & \multirow[t]{2}{*}{ P-value } \\
\hline & & Minimal & Mild & Moderate & M. Severe & Severe & \\
\hline \multirow[t]{7}{*}{ Chronic disease } & Asthma & $3(42.86)$ & I(I4.29) & I(I4.29) & $\mathrm{I}(\mathrm{I} 4.29)$ & I(I4.29) & \multirow[t]{7}{*}{0.036} \\
\hline & Cancer & $5(45.45)$ & I (9.09) & I (9.09) & $3(27.27)$ & I(9.09) & \\
\hline & Heart disease & $4(30.78)$ & $4(30.78)$ & $3(23.08)$ & $I(7.69)$ & $I(7.69)$ & \\
\hline & Diabetes & $30(33.33)$ & $29(32.22)$ & $13(14.44)$ & $8(8.89)$ & $9(10.0)$ & \\
\hline & Liver disease & 0.0 & 0.0 & 0.0 & 0.0 & I (100.0) & \\
\hline & Hypertension & $28(32.56)$ & $23(26.74)$ & $21(24.42)$ & $10(11.63)$ & $4(4.65)$ & \\
\hline & Kidney disease & $4(15.38)$ & $5(19.23)$ & $3(11.54)$ & $3(11.54)$ & II (42.3I) & \\
\hline \multirow[t]{2}{*}{ Employment status } & Employ & $20(9.95)$ & $54(26.87)$ & 43 (21.39) & 38 (I8.9|) & $46(22.89)$ & \multirow[t]{2}{*}{0.028} \\
\hline & Non-Employ & II(33.33) & $4(12.12)$ & $5(15.15)$ & $5(15.15)$ & $8(24.24)$ & \\
\hline \multirow[t]{3}{*}{ Information Source about COVID-19 } & $\mathrm{T} . \mathrm{V}$ and radio & $10(8.55)$ & 38 (32.49) & $27(23.08)$ & 21 (I7.95) & $21(17.95)$ & \multirow[t]{3}{*}{0.038} \\
\hline & Social media & $6(6.74)$ & $19(21.35)$ & $18(20.22)$ & $21(23.60)$ & $25(28.09)$ & \\
\hline & Health workers & II(39.29) & $5(17.86)$ & $4(14.29)$ & $3(10.7 I)$ & $5(17.86)$ & \\
\hline \multirow[t]{2}{*}{ Residence } & Urban & $68(32.38)$ & $55(26.19)$ & $40(19.05)$ & $27(\mid 2.86)$ & $20(9.52)$ & \multirow[t]{2}{*}{0.279} \\
\hline & Rural & $4(16.67)$ & $5(20.83)$ & $3(12.5)$ & $5(20.83)$ & $7(29.17)$ & \\
\hline
\end{tabular}

This study found that people who have more family members are more likely to develop anxiety than people with fewer family members, apart from people with chronic illnesses. This could be because many household members contact more people, which increases the stress of becoming infected. ${ }^{34,35}$ Chronic diseases increase the risk, especially in people with existing mental conditions or risk factors. ${ }^{7}$ This finding is consistent with studies from China and Ethiopia. ${ }^{29,34}$

Those who used social media as their main source of information about COVID - 19 were at least $28.09 \%$ more likely to develop severe anxiety during a stressful situation such as the current COVID -19 pandemic. Some authors ${ }^{35,36}$ linked the association between social media and the development of major depression to social media use during the COVID -19 pandemic. Psychological distress may increase in workers with chronic diseases and those who work with others. ${ }^{37,38}$ High work demands, low job control, a strong imbalance between performance and reward, low relational equity, low procedural equity, role stress, bullying, and low social support in the workplace are associated with a higher risk of common mental health problems. Married participants were more likely to develop depression compared to divorced and widowed participants. This is consistent with the findings of a recent study conducted by Ettman et al in the United States. ${ }^{39,40}$ Further, Krupa et $\mathrm{a}^{41}$ document that the associated anxiety of returning to normal society after a quarantine period led to some psychological problems and difficulties such as hallucinations. This could be explained by the stress associated with social status as a widow or divorcee. During the stressful phase of the pandemic, psychological support was provided by trained nurses and trained volunteers from non-governmental organizations.

Patients presented a fear related to the return to society and normal functioning after quarantine. Additionally, some study participants voiced concerns related to their mental health; some cases of hallucinations were reported.

This study calls urgent attention to reduce the impact of COVID 19 psychological consequences in patients with chronic diseases. Appropriate counseling during medical care of patients with chronic illnesses can reduce the COVID 19 associated psychological consequences. Addressing the related risk factors is the essential measure to improve the psychological status of patients with chronic diseases. 


\section{Conclusion}

COVID 19 pandemic affected the psychological status significantly on the psyche of uninfected people with chronic diseases in Sudan, and the significant associated factors were identified. Unique interventions are highly recommended for reducing the psychological implication of the COVID 19 pandemic.

\section{Abbreviations}

COVID-19, coronavirus disease; GAD7, generalized anxiety disorders; PHQ9, Patient Health Questionnaire 9.

\section{Ethics}

This study was conducted following the Declaration of Helsinki. Participants were enrolled in the study after providing informed consent. Informed consent contains relevant information and is conditional on participation in the study after signing the consent form. The (IRB) was obtained from the Faculty of Medical Sciences, Bakht Er-Ruda University, Sudan.

\section{Author Contributions}

All authors made a significant contribution to the work reported, whether that is in the conception, study design, execution, acquisition of data, analysis and interpretation, or in all these areas; took part in drafting, revising or critically reviewing the article; gave final approval of the version to be published; have agreed on the journal to which the article has been submitted; and agree to be accountable for all aspects of the work.

\section{Disclosure}

The authors report no conflicts of interest in this work.

\section{References}

1. Huang C, Wang Y, Li X, et al. Clinical features of patients infected with 2019 novel coronavirus in Wuhan, China. Lancet. 2020;395 (10223):497-506. doi:10.1016/S0140-6736(20)30183-5

2. World Health Organization. Emergency: coronavirus disease (COVID-19) pandemic. Available from: https://www.who.int/emergencies/diseases/ novel-coronavirus-2019. Accessed April 20, 2020.

3. Guessoum SB, Moro MR, Mallet J. The COVID-19 pandemic: do not turn the health crisis into a humanity crisis. Prim Care Companion CNS Disord. 2020;22(4). doi:10.3390/healthcare8020168

4. Asmundson GJG, Taylor S. Coronaphobia: fear and the 2019-nCoV outbreak. J Anxiety Disord. 2020;70:102196. doi:10.1016/j. janxdis.2020.102326

5. Thakur V, Jain A. COVID 2019-suicides: a global psychological pandemic. Brain Behav Immun. 2020;88:952. doi:10.1016/j.bbi.2020.04.062

6. Canady VA. Study finds COVID-19 survivors exhibit MH signs one month after treatment. Ment Health Wkly. 2020;30(32):1-3. doi:10.1002/ mhw. 32474

7. COVID C. Global cases by the Center for Systems Science and Engineering (CSSE) at Johns Hopkins University (JHU). Available from: https:// coronavirus.jhu.edu/COVID-19-basics/faq3. Accessed February 15, 2022.

8. Varatharaj A, Thomas N, Ellul MA, et al. Neurological and neuropsychiatric complications of COVID-19 in 153 patients: a UK-wide surveillance study. Lancet Psychiatry. 2020;7(10):875-882. doi:10.1016/S2215-0366(20)30287-X

9. Liguori C, Pierantozzi M, Spanetta M, et al. Subjective neurological symptoms frequently occur in patients with SARS-CoV2 infection. Brain Behav Immun. 2020;88:11-16. doi:10.1016/j.bbi.2020.05.037

10. Zarghami A, Farjam M, Fakhraei B, Hashemzadeh K, Yazdanpanah MH. A report of the telepsychiatric evaluation of SARS-CoV-2 patients. Telemed e-Health. 2020;26(12):1461-1465. doi:10.1089/tmj.2020.0125

11. Xie Q, Fan F, Fan XP, et al. COVID-19 patients managed in psychiatric inpatient settings due to first-episode mental disorders in Wuhan, China: clinical characteristics, treatments, outcomes, and our experiences. Transl Psychiatry. 2020;10(1). doi:10.1038/s41398-020-01022-x

12. Nalleballe K, Onteddu SR, Sharma R, et al. Spectrum of neuropsychiatric manifestations in COVID-19. Brain Behav Immun. 2020;88:71-74. doi:10.1016/j.bbi.2020.06.020

13. Chen Y, Jin YL, Zhu LJ, et al. The network investigation on knowledge, attitude and practice about novel coronavirus pneumonia of the residents in Anhui Province. Zhonghua Yu Fang Yi Xue Za Zhi. 2020;54:E004. doi:10.3760/cma.j.issn.0253-9624.2020.0004

14. Nigam C, Kumar A. COVID-19 pandemic: depression, anxiety go viral as nation observes lockdown. India Today; 2020. Available from: https:// www.indiatoday.in/mail-today/story/COVID-19-pandemic-depression-anxietyviral-nations-observeslockdown-1659774-2020-03-26. Accessed February 15, 2022

15. Rico-Uribe LA, Caballero FF, Martín-María N, Cabello M, Ayuso-Mateos JL, Miret M. Association of loneliness with all-cause mortality: a meta-analysis. PLoS One. 2018;13(1):e0190033. doi:10.1371/journal.pone.0190033

16. Waya JL, Ameh D, Mogga JL, Wamala JF, Olu OO. COVID-19 case management strategies: what are the options for Africa? Infect Dis Poverty. 2021;10(2):38-43. doi:10.1186/s40249-021-00795-7 
17. Aljak ER, Eldigail M, Mahmoud I, et al. The first laboratory-confirmed imported infections of SARS-CoV-2 in Sudan. Trans R Soc Trop Med Hyg. 2021;115(1):103-109. doi:10.1093/trstmh/traa151

18. Alyammahi SK, Abdin SM, Alhamad DW, Elgendy SM, Altell AT, Omar HA. The dynamic association between COVID-19 and chronic disorders: an updated insight into prevalence, mechanisms and therapeutic modalities. Infect Genet Evol. 2021;87:104647. doi:10.1016/j.meegid.2020.104647

19. Wang J, Wang JX, Yang GS. The psychological impact of COVID-19 on Chinese individuals. Yonsei Med J. 2020;61(5):438. doi:10.3349/ ymj.2020.61.5.438

20. Naeinian MR, Shairi MR, Sharifi M, et al. To study reliability and validity for a brief measure for assessing Generalized Anxiety Disorder (GAD-7). Sci J Clinic Psychol Personal. 2011;2(4):41-50.

21. Kroenke K, Spitzer RL, Williams JB, Monahan PO, Löwe B. Anxiety disorders in primary care: prevalence, impairment, comorbidity, and detection. Ann Intern Med. 2007;146(5):317-325. doi:10.7326/0003-4819-146-5-200703060-00004

22. Löwe B, Decker O, Müller S, et al. Validation and standardization of the Generalized Anxiety Disorder Screener (GAD-7) in the general population. Med Care. 2008;46:266-274. doi:10.1097/MLR.0b013e318160d093

23. Dadfar M, Kalibatseva Z, Lester D. Reliability and validity of the Farsi version of the Patient Health Questionnaire-9 (PHQ-9) with Iranian psychiatric outpatients. Trends Psychiatry Psychother. 2018;40(2):144-151. doi:10.1590/2237-6089-2017-0116

24. Ardestani MS, Ashtiani RD, Rezaei Z, Vasegh S, Gudarzi SS. Validation of Persian version of PHQ-9 for diagnosis of major depressive episode in psychiatric wards in Iran. Int J Appl Behav Sci. 2019;5(2):1-8. doi:10.22037/ijabs.v5i2.21094

25. Kumbeni MT, Apanga PA, Yeboah EO, Lettor IB. Knowledge and preventive practices towards COVID-19 among pregnant women seeking antenatal services in Northern Ghana. PLoS One. 2021;16(6):e0253446. doi:10.1371/journal.pone.0253446

26. Alkhamees AA, Alrashed SA, Alzunaydi AA, Almohimeed AS, Aljohani MS. The psychological impact of COVID-19 pandemic on the general population of Saudi Arabia. Compr Psychiatry. 2020;102:152192. doi:10.1016/j.comppsych.2020.152192

27. Kumar A, Arora A, Sharma P, et al. Is diabetes mellitus associated with mortality and severity of COVID-19? A meta-analysis. Diabetes Metab Syndr. 2020;14(4):535-545. doi:10.1016/j.dsx.2020.04.044

28. Wilson W, Raj JP, Rao S, et al. Prevalence and predictors of stress, anxiety, and depression among healthcare workers managing COVID-19 pandemic in India: a nationwide observational study. Indian J Psychol Med. 2020;42(4):353-358. doi:10.1177/0253717620933992

29. Wynne B, McHugh L, Gao W, et al. Acceptance and commitment therapy reduces psychological stress in patients with inflammatory bowel diseases. Gastroenterol. 2019;156(4):935-945. doi:10.1053/j.gastro.2018.11.030

30. Shahriarirad R, Erfani A, Ranjbar K, Bazrafshan A, Mirahmadizadeh A. The mental impact of COVID-19 outbreak: a population-based survey in Iran. Int J Ment Health Syst. 2021;15(1):1-3.doi:10.21203/rs.3.rs-23425/v3

31. Rajkumar RP. COVID-19 and mental health: a review of the existing literature. Asian J Psychiatr. 2020;52:102066. doi:10.1016/j.ajp.2020.102066

32. Gao P, Zhang H, Wu Z, Wang J. Visualising the expansion and spread of coronavirus disease 2019 by cartograms. Environ Plan A. $2020 ; 52$ (4):698-701. doi:10.1177/0308518X20910162

33. Soares CN, Zitek B. Reproductive hormone sensitivity and risk for depression across the female life cycle: a continuum of vulnerability? J Psychiatry Neurosci. 2008;33(4):331-343.

34. Abate BB, Kassie AM, Kassaw MW, Aragie TG, Masresha SA. Sex difference in coronavirus disease (COVID-19): a systematic review and meta-analysis. BMJ open. 2020;10(10):e040129. doi:10.1136/bmjopen-2020-040129

35. Yue S, Zhang J, Cao M, Chen B. Knowledge, attitudes and practices of COVID-19 among urban and rural residents in China: a cross-sectional study. J Community Health. 2021;46(2):286-291. doi:10.1007/s10900-020-00877-x

36. Chen SP, Chang WP, Stuart H. Self-reflection and screening mental health on Canadian campuses: validation of the mental health continuum model. BMC Psychol. 2020;8(1):1-8. doi:10.1186/s40359-020-00446-w

37. Rehman U, Shahnawaz MG, Khan NH, et al. Depression, anxiety and stress among Indians in times of COVID-19 lockdown. Community Ment Health J. 2021;57(1):42-48. doi:10.1007/s10597-020-00664-x

38. Wu JT, Leung K, Bushman M, et al. Estimating clinical severity of COVID-19 from the transmission dynamics in Wuhan, China. Nat Med. 2020;26 (4):506-510. doi:10.1038/s41591-020-0822-7

39. Ettman CK, Abdalla SM, Cohen GH, Sampson L, Vivier PM, Galea S. Prevalence of depression symptoms in US adults before and during the COVID-19 pandemic. JAMA netw open. 2020;3(9):e2019686. doi:10.1001/jamanetworkopen.2020.19686

40. Patel A, Jernigan DB, Abdirizak F. Initial public health response and interim clinical guidance for the 2019 novel coronavirus outbreak-United States, December 31, 2019-February 4, 2020. Morb Mortal Wkly Rep. 2020;69(5):140. doi:10.15585/mmwr.mm6905e1

41. Krupa S, Paweł W, Mędrzycka-Dąbrowska W, Lintowska A, Ozga D. Sleep disturbances in individuals quarantined due to SARS-CoV-2 pandemic in Poland: a mixed methods design study. Glob Adv Health Med. 2021;10:21649561211020707. doi:10.1177/21649561211020707

Journal of Multidisciplinary Healthcare

Dovepress

\section{Publish your work in this journal}

The Journal of Multidisciplinary Healthcare is an international, peer-reviewed open-access journal that aims to represent and publish research in healthcare areas delivered by practitioners of different disciplines. This includes studies and reviews conducted by multidisciplinary teams as well as research which evaluates the results or conduct of such teams or healthcare processes in general. The journal covers a very wide range of areas and welcomes submissions from practitioners at all levels, from all over the world. The manuscript management system is completely online and includes a very quick and fair peer-review system. Visit http://www.dovepress.com/testimonials.php to read real quotes from published authors.

Submit your manuscript here: https://www.dovepress.com/journal-of-inflammation-research-journal 